\section{O Hospital Proletário João Pessoa: limites e possibilidades para a saúde do trabalhador (Paraíba, anos 1930)}

\author{
The Hospital Proletário \\ in João Pessoa: limits and \\ possibilities for worker \\ healthcare (Paraíba, 1930s)
}

Leonardo Q.B. Freire dos Santos ${ }^{i}$

' Doutorando, Programa de Pós-graduação em História Social/ Universidade de São Paulo.

São Paulo - SP - Brasil

orcid.org/0000-0003-1450-1319

leonardoqbf@hotmail.com

Recebido em 5 set. 2019.

Aprovado em 4 mar. 2020.
SANTOS, Leonardo Q.B. Freire dos. O Hospital Proletário João Pessoa: limites e possibilidades para a saúde do trabalhador (Paraíba, anos 1930). História, Ciências, Saúde - Manguinhos, Rio de Janeiro, v.27, n.3, jul.-set. 2020, p.837-857.

\section{Resumo}

Discutimos a tentativa de organização do Hospital Proletário na capital da Paraíba nos anos 1930. Para tanto, problematizamos a cobertura do jornal A União sobre esse episódio. O envolvimento de diferentes atores trabalhadores, associações e médicos - revela a emergência de uma nova forma de pensar e praticar as políticas de saúde. Conforme o projeto varguista de construção nacional, tais ações visavam à formação de trabalhadores saudáveis, aptos para o mercado e úteis para a nação. Apesar de seu fracasso, o projeto do hospital evidencia as diferentes concepções sobre a saúde dos trabalhadores na Era Vargas. Apropriamonos dos conceitos de "interdependência sanitária", "medicina social", "cidadania regulada" e "trabalhismo".

Palavras-chave: saúde do trabalhador; história da saúde; instituições de saúde.

\section{Abstract}

We discuss the attempt to establish the Hospital Proletario in the capital of the state of Paraiba in the 1930s. To this end, we problematized the coverage in the newspaper A União on this episode. The involvement of different actors - workers, associations and physicians - reveals the emergence of a new way of thinking and implementing healthcare policies. According to the Vargas government's national construction plan, actions like this were intended to ensure healthy workers - ready for the market and useful for the country. Despite its failure, the hospital project provided evidence of the different concepts of worker health during the Vargas Era. We identified the concepts of "health interdependence," "social medicine," "regulated citizenship" and the "labor movement."

Keywords: worker healthcare; history of healthcare; healthcare institutions. 
$\mathrm{E}$ m setembro de 1930, quando a Paraíba ainda digeria os desdobramentos do assassinato de João Pessoa, o jornal $A$ União noticiou uma reunião da "maioria das sociedades proletárias desta capital ... a fim de acertar as providências para a fundação de um hospital nesta cidade" (Vai ser construído..., 2 set. 1930). Além de representantes trabalhistas, o evento contou com a participação do médico Nelson Carreira ${ }^{1}$ e do advogado Vidal Filho. ${ }^{2}$ A instituição receberia o nome do presidente morto "como a mais justa homenagem que os homens do trabalho podiam prestar ao inolvidável conterrâneo" (2 set. 1930).

Para angariar os recursos necessários à construção do Hospital Proletário João Pessoa, foi criada uma Confederação Operária Beneficente. Ela era formada pela reunião de diversas sociedades trabalhistas da capital e tinha como exclusiva finalidade a edificação e posterior administração do hospital. Era constituída por uma diretoria e por um conselho administrativo, sendo que este seria composto por representantes das associações que formavam a confederação.

A Confederação Operária Beneficente era formada por 19 associações trabalhistas de João Pessoa: União Operária Beneficente, idealizadora do projeto; Sociedade dos Artistas Mecânicos e Liberais; União Beneficente dos Operários e Trabalhadores; Sociedade Beneficente 2 de Setembro; Sociedade Beneficente dos Operários do Saneamento; União Beneficente das Senhoras; União Beneficente dos Proletários da Ilha Índio Piragibe; Centro dos Choferes da Paraíba do Norte; União dos Alfaiates; União Gráfica Beneficente Paraibana; Liga Protetora dos Pintores; Liga Protetora dos Metalúrgicos; Liga Protetora dos Sapateiros; Centro Proletário Beneficente; Aliança Proletária Beneficente; Sociedade Beneficente Alberto de Brito; União Beneficente dos Trabalhadores Ambulantes; União dos Retalhistas; e Colônia de Pescadores Vidal de Negreiros (Estatutos..., 17 set. 1930). No Quadro 1, apresentamos as informações que conseguimos reunir sobre essas associações.

Quadro 1: Associações engajadas no projeto do Hospital Proletário João Pessoa

\begin{tabular}{|l|c|c|}
\hline \multicolumn{1}{|c|}{ Associação } & Fundação & Núm. de sócios em 1932 \\
\hline União Operária Beneficente & 1919 & 119 \\
\hline Sociedade dos Artistas Mecânicos e Liberais & 1881 & 142 \\
\hline União Beneficente dos Operários e Trabalhadores & $?$ & $?$ \\
\hline Sociedade Beneficente 2 de Setembro & 1927 & $?$ \\
\hline Sociedade Beneficente dos Operários do Saneamento & 1928 & 48 \\
\hline União Beneficente das Senhoras & 1922 & 71 \\
\hline União Beneficente dos Proletários da Ilha Índio Piragibe & 1928 & 134 \\
\hline Centro dos Choferes da Paraíba do Norte & 1922 & 32 \\
\hline União dos Alfaiates & 1925 & 66 \\
\hline União Gráfica Beneficente Paraibana & 1927 & 26 \\
\hline Liga Protetora dos Pintores & 1927 & $?$ \\
\hline Liga Protetora dos Metalúrgicos & 1927 & $?$ \\
\hline Liga Protetora dos Sapateiros & 1926 & $?$ \\
\hline Centro Proletário Beneficente & $?$ & 251 \\
\hline Aliança Proletária Beneficente & 1927 & 74 \\
\hline Sociedade Beneficente Alberto de Brito & 1930 & $?$ \\
\hline União Beneficente dos Trabalhadores Ambulantes & 1930 & 166 \\
\hline União dos Retalhistas & 1917 & $?$ \\
\hline Colônia de Pescadores Vidal de Negreiros & $?$ & $?$ \\
\hline
\end{tabular}

Fonte: elaborado pelo autor com base em Gurjão (1994, p.149), Santana (2000, p. 222-223), Aires (2012, p.340-341), Figueirêdo (2016, p.63-66) e no Departamento Estadual de Estatística, da Paraíba (1933, p.159-177). 
As associações engajadas no projeto possuíam um perfil mutualista e foram fundadas entre o final do século XIX e o início do XX. Segundo Figueirêdo (2016, p.77-88), o boom do movimento associativista na capital da Paraíba ocorreu a partir dos anos 1910, no contexto da "modernização excludente" então implementada na cidade. Na época, a ausência de leis trabalhistas abria margem para a superexploração dos trabalhadores. Além disso, durante a Primeira República, o Estado brasileiro tratava as reivindicações proletárias como "caso de polícia". ${ }^{3}$ Assim, a criação de sociedades de ajuda mútua constituía uma forma de resistência possível contra um cenário de exclusão e exploração na busca de um futuro menos incerto. Nesse sentido, podemos pensar o projeto do Hospital Proletário como um desdobramento desse perfil mutualista das associações que o idealizaram, tendo em vista que, de modo geral, o objetivo delas era auxiliar na sobrevivência dos trabalhadores, sobretudo em casos de doença, acidentes e velhice (Hardman, Leonardi, 1991, p.100).

Mas é importante ressaltar que, desde o primeiro artigo de seus estatutos, a Confederação Operária deixou claro o seu objetivo de “Fundar o Hospital Proletário 'João Pessoa' na capital do Estado da Paraíba, cuja finalidade é a de servir à população de todo Estado ou a quem dele vier a necessitar" (Estatutos..., 17 set. 1930). Portanto, não foram estabelecidas restrições quanto à clientela do hospital. Aqui é oportuno lembrar que, naquele contexto, o exercício da cidadania estava atrelado ao que Santos $(1979$, p.75) conceituou como cidadania regulada, isto é,

o conceito de cidadania cujas raízes encontram-se, não em um código de valores políticos, mas em um sistema de estratificação ocupacional, e que, ademais, tal sistema de estratificação ocupacional é definido por norma legal. Em outras palavras, são cidadãos todos aqueles membros da comunidade que se encontram localizados em qualquer uma das ocupações reconhecidas e definidas em lei. ... A cidadania está embutida na profissão, e os direitos do cidadão restringem-se aos direitos do lugar que ocupa no processo produtivo, tal como reconhecido por lei. Tornam-se pré-cidadãos, assim, todos aqueles cuja ocupação a lei desconhece.

Os critérios para o exercício da cidadania regulada - trabalho formal e sindicalização ${ }^{4}$ - não foram definidos como critérios de acesso ao Hospital Proletário. Membros das associações que aderissem ao projeto teriam direito ao atendimento, mas a ideia era tornar o estabelecimento uma instituição voltada para os pobres, fossem eles trabalhadores ou não.

Neste artigo, problematizamos a tentativa de organização do Hospital Proletário na capital da Paraíba no início dos anos 1930. No âmbito estadual, essa é uma década de reordenamento político e econômico. Abordando esse contexto, Gurjão (1994, p.143) ressalta "a precariedade da indústria paraibana e a consequente insignificância do contingente operário". Ela também analisa o papel econômico "do Nordeste, e da Paraíba em particular, como região-satélite, subordinando-se cada vez mais ao Centro-Sul como fornecedor de mão de obra e de capital e consumidor dos manufaturados lá produzidos" (p.144). Além disso, a autora lembra que nos anos 1930 a Paraíba perdeu a liderança nacional na produção algodoeira, devido à concorrência paulista. Mesmo assim, o estado manteve-se como o maior produtor do Nordeste, o que assegurou "a predominância da oligarquia algodoeira no bloco dirigente do Estado" (p.121). Já a produção açucareira, segundo produto da economia paraibana, também encontrava-se em declínio, mal conseguindo atender a demanda local. 
Sem condições de fazer prevalecer seus interesses em âmbito nacional, as elites ${ }^{5}$ econômicas paraibanas acabaram conciliando com os projetos varguistas, de modo a conservar as bases de sua dominação política local (p.142). Essa conjuntura político-econômica ajuda a entender a relativa facilidade com que as diretrizes do Estado nacional para as classes trabalhadoras foram incorporadas e implementadas pelos grupos dirigentes da Paraíba, que se agarraram ao governo central para conservar seu poder local.

Nesse sentido, a principal questão que nos motivou a estudar o Hospital Proletário João Pessoa foi o que a história dessa instituição revela sobre os limites e possibilidades para a saúde dos trabalhadores no contexto do "trabalhismo" ${ }^{6}$ varguista.

Para contar essa história nos apropriamos das notícias veiculadas pelo jornal A União. ${ }^{7}$ Criado, em 1893, por Álvaro Machado, então presidente da Paraíba, e mantido desde então pelo governo do estado, esse periódico era produzido na capital e seguia uma linha editorial "governista", defendendo e divulgando as ações e a visão de mundo dos grupos hegemônicos. Assim, ele divulgava práticas e discursos que convergiam com os interesses das elites políticas locais. ${ }^{8}$ Além disso, nos anos 1930, A União era o principal meio de comunicação do saber médico entre o "público leigo", possibilitando-nos acessar os discursos médicos que circulavam na sociedade paraibana.

Maior veículo de comunicação da Paraíba naquela época, A União fornece a visão das elites políticas e econômicas sobre o Hospital Proletário. Lamentamos o fato de não termos encontrado fontes proletárias sobre o assunto. Mas, neste caso, tínhamos duas opções: problematizar as fontes oficiais, lendo-as de forma crítica, ou não produzir história alguma. Escolhemos o primeiro caminho. Ademais, o caráter intencional de A União, um jornal abertamente governista, não impossibilita sua apropriação como fonte. Como demonstrou Thompson (1981, p.36): “A evidência intencional (evidência oferecida intencionalmente à posteridade) pode ser estudada, dentro da disciplina histórica, tão objetivamente quanto a evidência não intencional ... No primeiro caso, as intenções são, elas próprias um objeto de investigação".

A análise das fontes sobre o Hospital Proletário demonstra que o projeto foi apoiado por diversos grupos sociais. Mas havia diferenças entre o que motivara cada um deles a engajar-se nesse empreendimento. Se para os trabalhadores tratava-se de reivindicar melhores condições de saúde, para os grupos hegemônicos o foco parece ter sido a (con)formação de uma mão de obra saudável, com vistas a aumentar sua produtividade e diminuir os riscos de contágio. É nesse contexto que entram as categorias de "interdependência sanitária" (Hochman, 2006) e "medicina social" (Foucault, 2017), sobre as quais nos aprofundaremos no decorrer do texto.

É nessa perspectiva que problematizamos a história do Hospital Proletário João Pessoa, procurando ressaltar o que esse episódio revela sobre o funcionamento da política de saúde do governo Vargas.

\section{Hospital Proletário João Pessoa: estabelecimento de saúde ou instituição de caridade?}

Nas fontes analisadas, o Hospital Proletário era definido como instituição de caridade e assistência social. Ao entrevistar o doutor Nelson Carreira, um dos idealizadores do projeto, o repórter de $A$ União definiu o "João Pessoa" como um "hospital cirúrgico destinado às 
classes pobres" (Hospital..., 23 fev. 1934). Celebrando a iniciativa e fomentando o consenso social em torno dela, A União publicou em 1933: "Não podia ser mais eloquente a simpatia com que nossa sociedade recebeu a ideia da fundação, nesta capital, do Hospital Proletário 'João Pessoa', hoje vitoriosa. Tantas e tão repetidas têm sido as demonstrações recebidas pelos seus fundadores, que nenhuma dúvida mais, sobre o futuro da novel instituição de caridade, poderá subsistir" (Posto Médico..., 10 jan. 1933).

Tal notícia soa irônica quando sabemos que o projeto arrastava-se desde $1930 \mathrm{sem}$ sucesso, e que, àquela altura, a Confederação Operária que o havia idealizado decidira investir os donativos recebidos na construção de um pequeno posto médico. A expectativa era de que ele fosse a semente do futuro hospital. Como veremos, seus membros ficaram só na esperança. Mas o que nos interessa nessa nota é a referência ao Hospital Proletário como instituição de caridade.

Essa percepção também parecia clara ao corpo médico que participou do projeto. Um dos clínicos que exerceram maior influência nesse processo foi o doutor Nelson Carreira, primeiro diretor da instituição, quando ela sequer havia saído do papel. Cirurgião e obstetra dos mais reconhecidos na capital, atuou como médico da Santa Casa de Misericórdia, onde provavelmente entrou em contato com os problemas e as demandas do proletariado. Discursando na inauguração do posto médico, o doutor Carreira fez questão de enfatizar: "Fui idealizador deste instituto de caridade" (A inauguração..., 13 dez. 1933). Esse entendimento também era partilhado pela elite política local. ${ }^{9} \mathrm{O}$ jornalista Manoel dos Anjos deixou isso bem claro ao analisar as instituições de assistência social que existiam na Paraíba em 1933. ${ }^{10}$ Após mencionar, entre outros, o Hospital da Santa Casa de Misericórdia e o Pronto-socorro da Assistência Pública Municipal de João Pessoa, ele explicou o que motivara o operariado a edificar seu Hospital Proletário:

Mas, como tudo isto não fosse o bastante, em matéria de assistência médica e hospitalar, os operários paraibanos, incansáveis no seu afã de quererem se beneficiar reciprocamente, sem, entretanto, ser necessário procurar aqueles invejáveis estabelecimentos, entenderam de, há cerca de três anos, organizar uma instituição semelhante àquelas, a que deram o nome acertadíssimo de 'Hospital Proletário João Pessoa' (Louvável iniciativa..., 30 set. 1933; destaque no original).

Não encontramos nenhuma fala operária a esse respeito. Mas o Estatuto da Confederação que idealizou o projeto previa, em seu artigo 19, que, "no caso de fracassar a construção do Hospital 'João Pessoa', o terreno, materiais, dinheiro, cofre e finalmente tudo que represente valor, serão divididos pelos estabelecimentos de caridade desta capital” (Estatutos..., 17 set. 1930). Mesmo tão sutil, não devemos desprezar esse indício.

Assim, podemos arriscar que o Hospital Proletário foi projetado como uma instituição de gestão da pobreza. Mais particularmente da pobreza doente. Aliás, o engajamento das elites políticas e econômicas na obra, por meio de donativos efusivamente celebrados por $A$ União, pode ser pensado para além do eventual exibicionismo social presente em algumas ações filantrópicas. É que o reconhecimento do caráter contagioso das doenças tornava os grupos dominantes da Paraíba mais sensíveis aos efeitos negativos da "interdependência sanitária" (Santos, 2015, p.75). 
Segundo Hochman (2006), a interdependência sanitária representa a dependência que existe nas relações sociais em função do caráter transmissível e dos efeitos coletivos de certas doenças. O reconhecimento dessa dependência tornou as elites políticas e econômicas mais receptivas a projetos de medicalização da sociedade, pois sua saúde também dependia das condições de vida dos mais pobres. Convergente com essa percepção, encontramos o artigo "Precisamos de hospitais", publicado por A União em 24 de maio de 1934. Além de estimular doações para o Hospital Proletário, o texto expressa a percepção das elites locais sobre o problema da interdependência sanitária:

É inegável que as construções majestosas ou simplesmente artísticas vão-se espalhando por toda a cidade, numa sequência admirável; vão, em suma, embelezando a capital, mas seria de bom alvitre que 'cuidássemos também das doenças que nos infelicitam e das chagas doloridas dos miseráveis' que, em número assustador, para uma pequena cidade, como é a nossa, "já se espalham pelos pontos mais movimentados da "urbes", constituindo o maior e mais sério de todos os perigos à higiene pública' (Precisamos de hospitais..., 24 maio 1934; destaques nossos em aspas simples; destaque no original em aspas duplas).

Não devemos esquecer que, na visão dos grupos dominantes, trabalhadores saudáveis eram sinônimo de produtividade. Assim, a saúde do pobre poderia ser duplamente positiva: diminuía o risco de contágio e contribuía para o "desenvolvimento econômico". Portanto, é possível pensar que o engajamento das elites locais em obras como o Hospital Proletário não se dava simplesmente como expressão de sentimentos humanitários, pois outros interesses também estavam envolvidos. Em artigo publicado por A União, o doutor Oscar de Castro, ${ }^{11}$ outro médico que colaborou com o Hospital Proletário, demonstrou que a percepção sobre os prejuízos econômicos e biológicos inerentes à "interdependência sanitária" estava no horizonte do corpo médico que participou do projeto:

Cheios de sofrimentos físicos e morais, abalados por males de influências depressivas sobre o sistema nervoso, não podendo suportar mais os revezes da existência os homens procuram o bálsamo para as suas chagas em delírios da imaginação em febre. 'E vem o vício, que rebaixa a moral e provoca o desânimo e a incapacidade para o trabalho'. Dessa terapêutica errônea decorre uma decadência certa e infalível. Desses fracassados, desses que não resistiram à gravidade dos lances imprevistos 'forma-se o batalhão de instáveis, de verdadeiros doentes morais, que procuram envenenar com a sua infelicidade o restante daqueles que ainda conservam a saúde do corpo e da alma. E é tal a interdependência entre os seres humanos', que a lei da solidariedade constitui a maior e mais humana das leis. 'Os homens estão unidos por um elo invisível, que identifica os seus destinos no bem ou no mal’ (Higiene..., 21 fev. 1932; destaques nossos).

Nessa perspectiva, a ameaça da doença - para suas vidas e seus projetos - tornou as elites políticas e econômicas mais preocupadas em relação à saúde dos pobres (Hochman, 2006, p.51). Expressando essa preocupação, o então governador da Paraíba, Argemiro de Figueirêdo,12 lamentou em mensagem à Assembleia Estadual que "as condições sanitárias das populações do litoral, brejo e caatinga continuam a reclamar do poder público providências urgentes. O impaludismo, o amarelão, a bouba e o tracoma grassam nessas regiões, estiolando preciosas energias do braço camponês" (Mensagem..., 2 out. 1935). 
Político ligado à oligarquia algodoeira-pecuária (Gurjão, 1994, p.177), Argemiro parecia ciente dos desdobramentos econômicos da interdependência sanitária.

Desse modo, o Hospital Proletário pode ser interpretado como uma instituição destinada aos pobres, fossem eles trabalhadores ou não. É que, no nosso recorte, o pobre e o trabalhador estavam ligados não apenas pela proximidade de situações socioeconômicas e culturais: força de trabalho efetiva ou em potencial, ambos eram alvo de um projeto de nação pautado na valorização do trabalho. Com esse objetivo, foram implementadas políticas públicas com forte conteúdo disciplinar, sobretudo nas áreas de saúde e educação. Por meio delas, o governo Vargas buscava "aperfeiçoar" essa parcela da população, visando (con)formar cidadãos/trabalhadores aptos para o mercado e úteis para a nação (Gomes, 1999, p.55).

\section{O problema da "falta" de recursos para a saúde do pobre}

Para viabilizar a construção do hospital, a Confederação Operária promoveu uma campanha de doações. Para isso, formou uma comissão que visitou constantemente o comércio e as autoridades locais entre 1930 e 1934 em busca de donativos (Posto Médico..., 27 dez. 1932). ${ }^{13}$ Essa mesma comissão visitou algumas cidades do interior em busca do apoio financeiro de outras associações operárias (Posto Médico..., 28 dez. 1932).

Membros da elite econômica também foram convidados a participar da comissão. Foi o que ocorreu com o comerciante Antônio Mendes Ribeiro, "capitalista e cidadão geralmente benquisto em nosso meio" que aceitou o "apelo da diretoria do H. Proletário 'João Pessoa', permitindo seja seu nome incluído entre os que compõem a comissão angariadora de donativos para a construção desse pio estabelecimento". Segundo A União, seu nome fora escolhido porque "em virtude das largas relações de amizade que desfruta no Estado, muito poderá fazer pela positivação da filantrópica iniciativa" (Hospital..., 18 fev. 1933). Na mesma linha, "senhoras e senhoritas de nossa alta sociedade" formaram um grupo de "Damas Protetoras" com o fim de promover eventos em prol do Hospital Proletário (Hospital..., 16 set. 1930).

Sobre os auxílios públicos, o governo do estado acenou timidamente. A Assembleia Estadual chegou a autorizar o governador "a subvencionar até a importância de vinte contos de réis (20:000\$000) ao Hospital Proletário 'João Pessoa'" (Assembleia Legislativa..., 25 set. 1930). Mas essa verba jamais foi liberada. O governo sugeriu a cessão de pavilhões de um hospital de isolamento, na época em construção, para instalação do "João Pessoa" (Hospital..., 4 dez. 1930), algo que também não se concretizou.

Não identificamos na documentação nenhuma ação do governo federal em prol do hospital. Esta "lacuna" suscita diversos questionamentos, visto que, na política social de Vargas, a saúde do trabalhador ocupava um papel estratégico. Por meio de ações no campo da legislação trabalhista, dos serviços médicos e da previdência social, o Estado pretendia preservar, recuperar e aumentar a capacidade produtiva do trabalhador:

Não se tratava unicamente de curar. Havia toda uma dimensão sanitária que buscava a proteção do corpo e da mente do trabalhador. No próprio interesse do progresso do país, deviam-se vincular estreitamente as legislações social e sanitária, já que o objetivo de ambas era construir trabalhadores fortes e sãos, com capacidade produtiva ampliada. ... [A saúde do trabalhador] era situada como o 'único capital com o qual ele concorre 
para o desenvolvimento nacional', constituindo-se assim em preciosa propriedade a ser mantida em uma sociedade de mercado (Gomes, 1994, p.226; destaque no original).

Sem o auxílio financeiro do Estado, erguer um hospital para os pobres na Paraíba dos anos 1930 tornou-se uma tarefa extremamente árdua. Sinalizando a dificuldade para viabilizar o projeto, a diretoria da Confederação Operária emitiu uma circular para os prefeitos da Paraíba "pedindo o seu apoio monetário à obra meritória em que se encontra empenhada". A justificativa para o pedido reforça a percepção do Hospital Proletário como uma instituição destinada aos pobres: "Esse apelo justifica-se, uma vez que aquelas autoridades lutam com sérias dificuldades, quando se trata de internar doentes pobres nos estabelecimentos hospitalares desta capital, dada a escassez de leitos nos mesmos verificada" (Hospital..., 4 maio 1934).

Trabalhadores de algumas empresas também uniram-se em prol do hospital. Os operários da Empresa Cearense, do setor de transportes, arrecadaram entre si $162 \$ 000$ (cento e sessenta e dois mil réis), valor remetido à diretoria do "João Pessoa" (Hospital..., 3 mar. 1933). Gesto semelhante foi feito pelos trabalhadores do Banco do Estado da Paraíba que cotizaram 200\$000 (duzentos mil réis) como doação ao hospital (Hospital..., 2 mar. 1934).

Não podendo custear o Hospital Proletário, a diretoria da Confederação Operária fez um apelo aos profissionais da saúde para que colaborassem voluntariamente com a instituição: “A diretoria do Hospital Proletário 'João Pessoa' dirigiu uma circular ao corpo médico da capital, solicitando de seus sentimentos humanitários uma hora de trabalho diário no Posto, em benefício dos pobres. Responderam já a esse apelo, calorosamente, acedendo, os nossos ilustres patrícios Drs. Newton Lacerda, ${ }^{14}$ Oscar de Castro, Evilásio Pessoa, ${ }^{15}$ Alfredo Monteiro ${ }^{16}$ e Nelson Carreira" (Posto Médico..., 27 dez. 1932).

Outros médicos também se comprometeram a trabalhar voluntariamente no hospital, caso dos doutores Lauro Wanderley, ${ }^{17}$ João Soares $^{18}$ e Octavio Soares ${ }^{19}$ (Posto Médico..., 12 jan. 1933). Além de médicos, enfermeiros (Posto Médico..., 5 jan. 1933) e dentistas (Hospital..., 19 mar. 1933) também engajaram-se no projeto. Sabendo que os profissionais da saúde também angariaram doações para o estabelecimento, fica evidente que o Hospital Proletário era uma bandeira mais do que legítima para eles.

Entre 1930 e 1934, A União publicou diversas notas enaltecendo os doadores e festejando as doações para o hospital. Entre os principais filantropos encontramos políticos, empresários e médicos. Algumas indústrias também aparecem como doadoras. ${ }^{20}$ Empresas de estados vizinhos, especialmente Pernambuco, fizeram o mesmo (Posto Médico..., 27 dez. 1932). Casas comerciais com representação na Paraíba, sobretudo as que revendiam medicamentos e produtos médicos, contribuíram com dinheiro e materiais (Hospital..., 11 mar. 1933). Até espetáculos artísticos foram organizados em prol da instituição. ${ }^{21}$

Enquanto isso, A União mantinha uma forte campanha "publicitária" para estimular novas doações. Trechos como o seguinte expressam o tipo de argumento utilizado pelo jornal: "Muito embora seja de iniciativa do operariado paraibano a construção do Hospital 'João Pessoa', é claro que necessita a grande classe do auxílio de todos, pois se trata de uma obra de vulto, muito superior às suas possibilidades" (Hospital..., 17 set. 1930). Pequenas notas publicadas na seção de propagandas do jornal apelavam para o senso de responsabilidade social dos leitores: “Auxiliar o Hospital Proletário 'João Pessoa' é um dever do qual nenhum 
paraibano deverá se eximir" (Hospital..., 10 fev. 1934). Se, por um lado, buscava estimular doações, tal campanha revelava as dificuldades para se viabilizar a instituição.

Os problemas financeiros enfrentados pelo Hospital Proletário encaminham para um discurso recorrente na retórica dos gestores paraibanos da época: a falta de recursos para a saúde pública. ${ }^{22}$ Um exemplo desse tipo de narrativa pode ser colhido no relatório do doutor Oscar de Castro (1936, p.3) sobre os serviços da Assistência Municipal23 de João Pessoa em 1935:

Com o desenvolvimento crescente desta capital, o que era perfeito há anos atrás, já agora se apresenta deficiente. A Assistência Municipal, desde o seu início, vem recebendo melhoramentos anuais, sem que, entretanto, ainda se tenha podido executar um plano completo de reforma ... Se o serviço de Assistência se vem mantendo, de certo modo, a contento, isto significa, não que as suas atuais instalações sejam satisfatórias, mas que um esforço sobre-humano dos diversos auxiliares deste serviço vem suprindo o que é deficiente na parte material.

Queixa semelhante foi feita pelo doutor Walfredo Guedes Pereira, ${ }^{24}$ chefe da Diretoria de Saúde Pública da Paraíba, na época o órgão responsável pelo setor no estado. Em seu relatório referente a 1933, criticou a falta de autonomia administrativa e a escassez de recursos do departamento que dirigia: "A escassez orçamentária; ... a deficiência de médicos e de outros funcionários, principalmente para serviços especializados ... e a falta de independência no que diz respeito à parte técnica e administrativa deste departamento, continuavam sendo grandes entraves ao seu desenvolvimento e maior eficiência" (Relatório..., 4 maio 1934).

A limitação de recursos não era uma exclusividade do Hospital Proletário: tratava-se de um problema também enfrentado pelos gestores da saúde pública paraibana nos anos 1930. Ou pelo menos era essa a narrativa operacionalizada para justificar a precariedade dos serviços oferecidos à população. Infelizmente, não temos dados suficientes para analisar a execução do orçamento estadual. Mas Gurjão (1994, p.121-122) nos informa que, no início dos anos 1930, a arrecadação estadual foi fortemente impactada pela queda nas vendas dos dois principais produtos da Paraíba, o algodão e o açúcar. Além disso, esse cenário de crise foi agravado pelos efeitos da seca de 1932. Expressando essas dificuldades, o orçamento da Diretoria de Saúde Pública da Paraíba foi reduzido, passando dos 911:886\$000 (novecentos e onze contos e oitocentos e oitenta e seis mil réis) orçados em 1932 (Decreto n.244..., 1 jan. 1932) para 842:430\$000 (oitocentos e quarenta e dois contos e quatrocentos e trinta mil réis) em 1933 (Decreto n.355..., 1 jan. 1933).

Porém, outra forma possível de se problematizar a exiguidade de recursos públicos para uma política social é refletindo a partir da noção de "cálculo do dissenso", cunhada por Santos (1979, p.125):

Impedidos de ignorar a existência de problemas sociais, os governantes são compelidos a administrá-los. ... As imposições da dinâmica dos conflitos, por um lado, e as necessidades de garantir a reprodução ampliada (acumulação) da riqueza social, por outro, induzem os governos a exercer permanentemente o que se poderia chamar de 'cálculo do dissenso', isto é, a taxa de injustiça, em favor da acumulação, que será socialmente tolerada, ou, conversamente, a magnitude dos recursos que se podem subtrair à acumulação, em favor da equidade, sem prejuízo catastrófico para o processo ampliado de reprodução. 
Ainda conforme Santos (1979, p.127), na gestão dos problemas sociais em uma sociedade capitalista, os governantes precisam equacionar dois objetivos polares: acumulação econômica e equidade social. Nessa tarefa, deverão promover a reprodução ampliada da riqueza e enfrentar a estrutura geral de carências sociais, que podem ou não se transformar em demandas, dentro das limitações impostas pelos recursos disponíveis. Nesse sentido, a execução do orçamento público também pode ser pensada como um problema de cálculo político: na deliberação sobre o "que" e o "como" fazer, que não está dada a priori, os decisores precisam "calcular o dissenso" tolerado pelos diferentes agentes sociais: "Consequentemente, não obstante a retórica dos que tomam decisões, ou de seus críticos, o que se encontra por trás das escolhas de políticas específicas, cujos parâmetros são a escala de preferências dos decisores e a magnitude dos recursos disponíveis face à magnitude das carências reconhecidas, é, em realidade, um cálculo do dissenso tolerável pela comunidade" (Santos, 1979, p.138).

Além disso, não devemos esquecer que a construção das políticas sociais é mediada pelas relações de poder e pela capacidade variável de mobilização dos diferentes agentes sociais. E, como demonstrou Fonseca (2007, p.93-162), o formato da política de saúde na Era Vargas resultou de conflitos e negociações entre diferentes atores, cada um com capacidade variável de influenciar o processo: o poder central, o poder legislativo (durante o período constitucional), as oligarquias locais, além das corporações e dos grupos de interesse com representação junto aos poderes constituídos.

Com base nessas reflexões, o parco engajamento dos poderes públicos na construção do Hospital Proletário pode ser interpretado de duas formas: talvez seus idealizadores não tivessem logrado transformar o projeto em uma demanda legítima ante os agentes políticos; ou quem sabe os decisores tenham calculado que os benefícios sociais de tal estabelecimento não justificavam a subtração de recursos ao processo de acumulação. Também não podemos descartar a possibilidade de ambos os fatores terem influído no processo. Mas aqui nos encontramos no território das conjecturas, haja vista que as fontes não abordam abertamente o tema. Contudo, o jornal A União, em artigo citado anteriormente, fornece algumas pistas sobre a postura do poder estatal em relação ao Hospital Proletário. Segundo o articulista, o projeto estava "arrastando-se como em verdadeira 'via-crúcis', contando com a boa vontade de abnegados para somente assim ser levado avante" (Precisamos de hospitais..., 24 maio 1934). Como podemos perceber, o porta-voz do governo estadual reconhecia que o sonho de um Hospital Proletário em João Pessoa estava àquela altura entregue à "boa vontade de abnegados".

Além disso, analisando a documentação disponível sobre o episódio, a impressão que fica é a de que não houve um maior esforço do governo estadual para concretizar o projeto. Isso foi evidenciado, como mostramos anteriormente, pela não liberação da verba que a Assembleia Estadual havia destinado ao hospital. O mais curioso, porém, é que a falta de um maior empenho do poder estadual para viabilizar a instituição ocorreu justamente durante a "montagem" do "trabalhismo" varguista. Dessa forma, é no mínimo surpreendente que o Hospital Proletário João Pessoa não tenha angariado maior engajamento dos agentes políticos, tendo em vista que ele fora idealizado durante a construção de uma ideologia política pautada exatamente na valorização do trabalho e do trabalhador. Em todo caso, esse 
episódio evidencia a possibilidade de "fissuras" no projeto varguista de superar os graves problemas socioeconômicos do país, transformando "o homem em cidadão/trabalhador, responsável por sua riqueza individual e também pela riqueza do conjunto da nação" (Gomes, 1999, p.55).

\section{Possíveis interesses em torno do projeto}

Como vimos, o Hospital Proletário João Pessoa foi projetado para atender aos pobres em geral. Mas, em certo sentido, sua idealização indica uma preocupação com a saúde das classes trabalhadoras, ou, mais precisamente, com a saúde daqueles cujo único bem é a força de trabalho. ${ }^{25}$

Por outro lado, as análises de Chalhoub (2012) e Diniz (2004) evidenciam que o fim da escravidão em 1888 gerou para as elites econômicas a necessidade de criar novas estratégias de controle da força de trabalho. Com Gomes (1994, p.226), vimos que durante a Era Vargas as políticas de saúde também participaram desse esforço de (con)formação de um novo trabalhador, saudável e produtivo. O engajamento dos grupos dominantes nesse processo pode ser visualizado no caso do Hospital Proletário João Pessoa. Podemos notá-lo quando lembramos as ações e doações das elites econômicas em prol do estabelecimento; ou quando sabemos que, desde o início, a Confederação Operária que idealizou a instituição contava com a liderança de integrantes dessas mesmas elites, com destaque para os médicos.

Por seu turno, não podemos negligenciar o protagonismo das classes trabalhadoras. A união de diversas associações em torno do projeto, além do engajamento de trabalhadores em prol do estabelecimento, revelam o agir do proletariado na luta por melhores condições de saúde. A magnitude e a complexidade do hospital idealizado evidenciam que a pauta da saúde também estava entre as demandas do proletariado paraibano.

Outra possibilidade é pensar o Hospital Proletário como desdobramento do que Foucault (2017, p.169) chamou de medicina social ${ }^{26}$ da força de trabalho. Segundo o autor, ela apareceu no século XIX, primeiramente na Inglaterra, e pode ser definida como "um controle da saúde e do corpo das classes mais pobres para torná-las mais aptas ao trabalho e menos perigosas às classes mais ricas". Essa intenção parece informar a fala do doutor Nelson Carreira na cerimônia de posse do doutor Newton Lacerda como diretor do João Pessoa. Abordando a finalidade do Hospital Proletário, ele fez a seguinte análise: "Não era justo que o proletário, enfermo, ficasse sujeito às vicissitudes da sorte, sem o necessário socorro médico. Ele precisava ter seu hospital, pois não podia conceber que um homem do trabalho, quando atingido na sua saúde, tivesse de implorar, da boa vontade de terceiros, para poder dispor da indispensável assistência hospitalar" (Hospital..., 7 fev. 1933).

Em pesquisa anterior (Santos, 2015), mostramos que práticas e discursos da medicina social da força de trabalho já circulavam na Paraíba desde os anos 1910, informando as ações da política de saúde. É importante esclarecer que ela possui um forte conteúdo de interdependência, uma vez que a saúde do proletariado significaria a segurança do rico. Assim, para se beneficiar da assistência médica, o trabalhador precisaria se submeter a uma série de controles. Surge então uma "assistência controlada", que é 
tanto uma maneira de ajudar os mais pobres a satisfazer suas necessidades de saúde, sua pobreza não permitindo que o façam por si mesmos, quanto um controle pelo qual as classes ricas ou seus representantes no governo asseguram a saúde das classes pobres e, por conseguinte, a proteção das classes ricas. Um cordão sanitário autoritário é estendido no interior das cidades entre ricos e pobres: os pobres encontrando a possibilidade de se tratarem gratuitamente ou sem grande despesa, e os ricos garantindo não serem vítimas de fenômenos epidêmicos originários da classe pobre (Foucault, 2017, p.166-167).

Foucault (2017, p.170) considera que a medicina social da força de trabalho "foi a que teve futuro" na maioria dos países capitalistas, pois ela permitiu a realização de três sistemas médicos articulados: "uma medicina assistencial destinada aos mais pobres, uma medicina administrativa encarregada de problemas gerais como a vacinação, as epidemias etc., e uma medicina privada que beneficiava quem tinha meios para pagá-la". Sabendo que desde o final do século XVIII o hospital tornara-se um lugar de formação e transmissão do saber médico, ${ }^{27}$ podemos discutir se um hospital para pobres também não teria a função de produzir conhecimentos que pudessem ser aplicados na clínica privada. Nesse caso, o corpo do pobre funcionaria como território de experimentação do saber médico.

No caso do Hospital Proletário João Pessoa, mais um discurso do doutor Nelson Carreira nos conduziu a essa análise. Na cerimônia de inauguração do posto médico da instituição, em 10 de dezembro de 1933, Carreira foi um dos oradores oficiais. Entre outros assuntos, ele ressaltou que "esta casa será o abrigo dos desamparados. Nela a classe paupérrima dos proletários encontrará lenitivo quando a doença lhe afligir e o trabalho se torne pesado" (A inauguração..., 13 dez. 1933). Mas além de definir o público-alvo da instituição, Carreira também expressou seu pensamento sobre a função do hospital como lugar de produção de saber médico:

[O hospital] É o verdadeiro laboratório da ciência. Nele, o espírito científico, depurado dos vícios materiais de quem o exerce, olha observando, com o interesse quase divino de renovar, descobrir, progredir, melhorar a ciência contemporânea. O hospital é o Templo. A ciência o Altar. Nele, 'médicos e doentes confundidos num grande sacrifício, queimam-se como oferenda magnífica' da humanidade de hoje em benefício da humanidade de amanhã (A inauguração..., 13 dez. 1933; destaque nosso).

Reforçando essa percepção, o doutor Carreira ainda enfatiza: “As nossas portas deverão estar abertas em igualdade de condições para todo médico que quiser estudar. Nesta instituição, a antiguidade não será posto, porque os métodos científicos renovadores não devem ser prejudicados" (A inauguração..., 13 dez. 1933).

As fontes consultadas não permitem assegurar essa produção de saber no Hospital Proletário. ${ }^{28}$ Mas as palavras do doutor Carreira - proferidas em uma celebração pública da instituição, por um de seus principais líderes - possibilitam pensar que a produção de conhecimentos médicos também estava no horizonte dos seus idealizadores. Nesse caso, o Hospital Proletário não deve ser tomado como uma política social restrita aos pobres, pois os ricos tirariam dele pelo menos três benefícios: trabalhadores saudáveis; menos riscos de epidemias; médicos particulares mais qualificados. Esse ganho triplo talvez ajude a compreender o engajamento das elites políticas e econômicas no projeto. 


\section{Apropriações e usos políticos do João Pessoa}

Outro aspecto importante sobre o Hospital Proletário foi a apropriação do projeto pelas elites políticas e econômicas. Um primeiro indício nos é dado pelo tom publicitário com que $A$ União noticiou os donativos à instituição. Em alguns casos, como nas doações de medicamentos por farmácias e laboratórios comerciais, a notícia transformava-se em propaganda: a caridade confundia-se com o business e o doar tornava-se estratégia de venda. Seria o capitalismo tirando mais um proveito da causa proletária? A citação a seguir permite-nos refletir sobre isso:

É com incontida satisfação que anotamos também a presteza com que 'os mais afamados laboratórios nacionais' têm, pelos seus agentes em nossa praça, contribuído para a farmácia do Posto. Ainda ontem o representante para o norte do país da 'conceituada firma carioca Hyman Rinder \& Cia.', de presente, nesta capital, procurado por membros da diretoria do 'João Pessoa', prontificou-se imediatamente a solicitar da mesma a seguinte valiosa dádiva: 200 vidros de Fosfato Ácido 'Horsford', 'universalmente empregado para dispepsia, indigestões, prostração mental e física, neurose e como tônico geral'; 200 vidros de 'Gestex', que é um 'novo e já acreditado medicamento para o aparelho digestivo, combatendo eficazmente a hiperacidez' e piroses e possuindo ainda as virtudes de fazer cessar o calor produzido no estômago e de absorver o gás no trato intestinal, nas dispepsias etc.; 50 vidros de pó antiasmático, 'Himrod' ... 'usado em todo o mundo com o mais absoluto êxito', e 200 latas do 'afamado leite em pó' irradiado 'Dryco', 'utilíssimo na falta do leite materno e já hoje tão empregado, pela sua superior qualidade', que não necessita mais de reclame. ... Contribuindo com tão importante donativo, os Srs. Hyman Rider \& Cia. podem ter a certeza de haver concorrido para uma obra de benemerência e alta finalidade social (Hospital..., 21 fev. 1933; destaques nossos).

A citação acima é representativa do tom publicitário com que $A$ União abordou ${ }^{29}$ os donativos empresariais ao Hospital Proletário. Percebe-se, assim, mais uma forma de apropriação da saúde do trabalhador pelas elites econômicas.

Também não podemos esquecer que projetos como o Hospital Proletário eram oportunidades para que as elites políticas e econômicas reforçassem seu status social por meio da exibição pública da caridade. Ou mais propriamente, como demonstrou Caponi (2000, p.21), permitia-lhes estabelecer "uma divisão binária entre aquele que se engrandece ao realizar a ação [caridosa] e aquele que se diminui ao recebê-la", reforçando hierarquias e relações de poder.

No caso do Hospital Proletário isso fica evidente, por exemplo, no tom de "celebração pública" com que $A$ União noticiava os donativos à instituição. Outro exemplo foi o festival artístico e esportivo organizado em abril de 1934 pela guarnição do Exército na Paraíba, em parceria com os médicos do Hospital Proletário, em prol da instituição.

A programação do evento foi dividida em duas partes. Na noite de 14 de abril, um concerto musical no cineteatro Rio Branco, que contou com a presença de autoridades e integrantes das elites locais, quando se apresentaram as bandas de música do $22^{\circ}$ Batalhão de Caçadores do Exército, da Força Pública do Estado e da Escola Normal da capital. Na tarde do dia seguinte, várias provas esportivas no estádio do Esporte Clube Cabo Branco, 
com direito a ice cream vendido por um grupo de "gentis senhoritas" da "alta sociedade" paraibana. A renda obtida com a venda de ingressos e produtos foi revertida para o Hospital. ${ }^{30}$

O que mais chama atenção na análise desse evento é a exclusão do proletariado, tanto da organização quanto do festival em si. Tratou-se de um evento social produzido pelas elites e para as elites. De proletário restou apenas o nome da instituição a que seriam revertidos os donativos. Apesar dos ganhos evidentes para o hospital, mais uma vez a causa operária foi apropriada para que também favorecesse, de alguma forma, os grupos dominantes.

\section{E, no fim das contas, o que a história do João Pessoa evidencia?}

Apesar do engajamento de diferentes grupos sociais, o Hospital Proletário não saiu do papel. ${ }^{31}$ A União atribuiu à "Revolução de outubro de 1930 e o largo período de reconstrução nacional, que se lhe seguiu" a dificuldade para viabilizar esse "projeto grandioso" (A próxima instalação..., 21 dez. 1932).

Diante desse cenário, em dezembro de 1932, a Confederação Operária decidiu utilizar parte dos recursos doados ao hospital para abrir um posto médico. Ele seria instalado na sede da confederação, à avenida Benjamin Constant 117, "no bairro proletário do Jaguaribe" (A próxima instalação..., 21 dez. 1932). A ideia era dotar a capital de um lugar "onde receberão os necessitados, além dos socorros clínicos, os medicamentos receitados" (A próxima instalação..., 21 dez. 1932). Ao mesmo tempo, o posto foi pensado como forma de viabilizar a edificação do futuro hospital: "Foi o modo mais inteligente de prestar, imediatamente, serviços reais às classes laboriosas, tornando-os, ao mesmo tempo, preciosa fonte de renda para a construção do futuro hospital, pois os beneficiados, na medida de suas posses, contribuirão de modo decisivo para a caixa filantrópica da instituição" (A próxima instalação..., 21 dez. 1932).

A expectativa era de que o posto médico começasse a funcionar a partir de janeiro de 1933 (Posto Médico..., 5 jan. 1933). Mas somente em 10 de dezembro de 1933, "embora com grande sacrifício" (O Hospital..., 10 dez. 1933), ele foi inaugurado (Benemérita realização..., 12 dez. 1933). Os serviços prestados eram principalmente os da medicina curativa: exames médicos, prescrição de receitas, realização de curativos, aplicação de injeções, distribuição de remédios e pequenas intervenções cirúrgicas.

Os médicos que se revezavam nos plantões do posto eram voluntários, podendo-se mencionar os doutores Aluisio Raposo, ${ }^{32}$ Nelson Carreira e Newton Lacerda. ${ }^{33}$ Ainda conseguimos descobrir que o posto médico oferecia um serviço de clínica infantil (Hospital..., 26 jan. 1934).

Apesar do tom "ufanista" de A União, ficam evidentes as limitações no atendimento do posto e as dificuldades para mantê-lo funcionando. Um indício desses problemas são os reiterados apelos publicados pelo jornal conclamando os paraibanos a continuar com as doações. ${ }^{34} \mathrm{Na}$ própria inauguração do posto, a fala de uma liderança proletária indicou os desafios enfrentados pelas classes trabalhadoras no campo da saúde: “Terminando a solenidade, o Sr. Elísio José de Souza [presidente da Confederação Operária] dirige algumas palavras ao conceituado corpo médico da cidade, fazendo-lhe um apelo para que não falte nunca sua colaboração à cruzada que se inicia; para que jamais desampare o operariado, classe pobre que com seu suor tanto concorre para o progresso geral" (Benemérita realização..., 12 dez. 1933). 
O ponto a ressaltar é que, apesar do engajamento de diferentes agentes sociais, o projeto do Hospital Proletário não prosperou. A partir de 1935, não encontramos mais nenhuma referência a seu respeito - nem na bibliografia, nem documentação. Com efeito, o hospital, a Confederação Operária e até mesmo o posto médico desaparecem completamente dos registros históricos. ${ }^{35} \mathrm{O}$ que teria provocado seu fracasso justamente na era do "trabalhismo", quando o Estado brasileiro promoveu uma ideologia política de valorização do trabalho e das classes trabalhadoras?

No início deste artigo, mostramos que o Hospital Proletário jamais se definiu como uma instituição restrita aos trabalhadores. Vimos também que os diversos segmentos das elites locais encaravam o João Pessoa como um estabelecimento para os pobres em geral. Ao entrevistar o doutor Nelson Carreira, o repórter de $A$ União chegou a afirmar que a instituição fora idealizada "para atender à massa de doentes pobres que cresce cada dia" (Hospital..., 23 fev. 1934).

Assim, fica evidente que o Hospital Proletário não foi projetado como uma instituição específica para trabalhadores, muito menos como um estabelecimento de saúde que atenderia somente aqueles com carteira assinada e filiação nos sindicatos reconhecidos pelo estado. Ele sequer foi percebido assim pelos contemporâneos.

Enquanto existiu, o João Pessoa foi construído discursivamente como um espaço de cura para o doente pobre, fosse ele trabalhador formal ou força de trabalho em potencial. Somada ao quadro de crise econômica e política que afetou a Paraíba no Pós-1930, esta dificuldade em "purificar" ${ }^{36}$ seu público-alvo em conformidade com o conceito de cidadania regulada talvez tenha inviabilizado a iniciativa no contexto do "trabalhismo" varguista.

Apesar de seu fracasso, o projeto do Hospital Proletário e o engajamento de diversos agentes sociais em sua viabilização revelam a convergência de diferentes processos históricos em torno da saúde do trabalhador: a luta do proletariado por melhores condições de vida; a percepção da interdependência sanitária por parte das elites políticas e econômicas; e a existência de uma medicina social da força de trabalho na Paraíba.

\section{NOTAS}

${ }^{1}$ Nelson Carreira formou-se em odontologia no Recife (1920) e em medicina em Salvador (1929). Após breve estada nas cidades do Crato (CE) e Cajazeiras (PB), estabeleceu-se em João Pessoa como cirurgião e obstetra, onde também se tornou membro da Sociedade de Medicina e Cirurgia. Além disso, atendia o proletariado no Hospital da Santa Casa de Misericórdia, o que provavelmente contribuiu para seu engajamento no Hospital Proletário (Nóbrega, 1979, p.145).

${ }^{2}$ Francisco Vidal Filho formou-se em direito no Recife (1929). Além de advogado, trabalhava como redator do jornal A União. Também era sócio e colaborador do Instituto Histórico e Geográfico Paraibano.

${ }^{3}$ Sobre a repressão contra as reivindicações trabalhistas, cf. Hardman e Leonardi (1991, p.158) e Santos (1979, p.73).

${ }^{4}$ Segundo Gomes (1994, p.150-151), entre 1933 e 1934 o governo Vargas atrelou os conceitos de trabalho e cidadania. Assim, o trabalho formal, validado pelo registro na carteira de trabalho, e a participação em sindicato reconhecido pelo Estado tornaram-se os principais critérios de acesso aos direitos sociais. Era a lógica do "só quem tem ofício tem benefício" (p.163).

${ }^{5}$ Trabalhamos o conceito de "elite" conforme Pereira Neto (2001, p.32). Segundo esse autor, "os componentes da elite seriam as pessoas que dispõem de maior acesso aos valores e ao seu controle e ocupam as mais altas posições numa determinada sociedade. A quantidade de elites seria, assim, tão grande quanto a de valores. 
Além da elite de poder, ou elite política, existiriam as elites de riqueza, respeitabilidade e conhecimentos". Considerando a Paraíba dos anos 1930, Gurjão (1994, p.103-142) demonstrou a hegemonia política e econômica dos grupos ligados às oligarquias algodoeira-pecuária e açucareira, que então controlavam a máquina estatal. Quanto à elite intelectual, ela também estava ligada aos grupos que exerciam o poder político e econômico no estado, haja vista que o acesso à formação acadêmica, indispensável para o exercício desse papel social, era privilégio dos segmentos abastados da sociedade.

${ }^{6}$ Noção desenvolvida por Gomes (1994, p.162-166) em seu estudo sobre as relações entre o governo Vargas e as classes trabalhadoras. Segundo a autora, o "trabalhismo" foi uma ideologia política, estruturada pelo Estado, visando estabelecer um vínculo político entre o presidente e os trabalhadores. Para tanto, o governo apropriou-se dos resultados simbólicos das lutas proletárias para constituir uma noção de cidadania fundada nos direitos sociais do trabalho. Esses ganhos materiais eram apresentados pela propaganda oficial como uma "doação", estimulando-se a "reciprocidade" dos trabalhadores em relação ao "Estado paternalista". Contudo, o "trabalhismo" não é analisado apenas como uma estrutura de dominação: o que ocorria era uma relação de "troca", em que os trabalhadores também eram agentes do processo.

${ }^{7}$ Entre os periódicos paraibanos que sobreviveram à ação do tempo, A União foi o único que produziu copioso material sobre o Hospital Proletário João Pessoa. Outros jornais da época limitaram-se a publicar notas informativas sobre o assunto.

${ }^{8}$ Para mais informações sobre A União, ver Araújo (1986, p.255-273) e Martins (1977).

${ }^{9}$ Além dos trechos citados, essa definição aparece em outras notícias publicadas por A União, a exemplo de: Hospital... (7 fev. 1933, 9 fev. 1933, 23 fev. 1934), O Hospital... (10 dez. 1933), Amparo... (18 abr. 1934).

${ }^{10}$ Tal rede de instituições fora constituída no início do século XX, quando a capital paraibana passou por um processo de reformas urbanas que assumiu feições excludentes e disciplinadoras. Ver Soares Júnior (2011) e Chagas (2004).

${ }^{11}$ Oscar de Castro formou-se em medicina no Rio de Janeiro (1923). De volta à Paraíba, passou a atuar na capital como pediatra. Entre 1923 e 1947 dirigiu o Serviço Municipal de Assistência Pública e o Hospital de Pronto-socorro de João Pessoa. Além de sua carreira no serviço público, foi presidente da Sociedade de Medicina e Cirurgia, atuando como um dos principais colaboradores de seu periódico, a Revista Medicina. Sua influência no campo intelectual pode ser confirmada pela recorrente presença de seus textos no jornal A União, bem como por sua trajetória como membro do Instituto Histórico e Geográfico Paraibano (Nóbrega, 1979, p.146-147).

12 Argemiro de Figueirêdo esteve à frente do Executivo estadual como governador eleito pela Assembleia Legislativa (1935 a 1937) e como interventor nomeado por Vargas (1937 a 1940). Sua gestão foi marcada pela conciliação das oligarquias locais e pela "modernização conservadora" da economia, quando se buscou diversificar a produção preservando-se as estruturas tradicionais de dominação (Santana, 2000, p.152, 181).

${ }^{13}$ Os integrantes da comissão eram Manuel Pereira dos Anjos, Elysio José de Souza, Joaquim Pereira do Nascimento e Manuel Caetano da Silva. Infelizmente, não encontramos informações sobre esses trabalhadores.

${ }^{14}$ Natural de Pernambuco, Newton Lacerda formou-se em medicina no Rio Janeiro (1922). Nesse mesmo ano chegou à Paraíba designado como assistente do laboratório de pesquisas da Comissão Federal de Saneamento e Profilaxia Rural. Estabelecido na capital, montou um consultório de clínica geral. Nos anos 1930, tornou-se um empresário bem-sucedido no ramo dos hospitais particulares. No setor público, dirigiu o Hospital Colônia Juliano Moreira e o Hospital Oswaldo Cruz, ambos na capital. Também atuou no Ambulatório do Instituto de Aposentadoria e Pensões dos Comerciários. Foi membro da Sociedade de Medicina e Cirurgia e assíduo colaborador do jornal A União. Integrante da elite econômica local, elegeu-se deputado estadual em 1934 pelo Partido Progressista, hegemônico na Paraíba durante a fase constitucional da Era Vargas (Nóbrega, 1979, p.178-181).

${ }^{15}$ Pouco sabemos sobre o doutor Evilásio Pessoa, apenas que era formado pela Faculdade de Medicina do Rio de Janeiro e que, nos anos 1930, possuía um consultório em João Pessoa especializado em doenças do aparelho digestivo (Dr. Evilásio..., 17 mar. 1932).

${ }^{16}$ Alfredo Monteiro era formado em farmácia pela Faculdade da Bahia e em medicina pela do Rio de Janeiro. Atuou principalmente no setor público, notadamente na Diretoria de Saúde Pública da Paraíba, onde exerceu o cargo de farmacêutico e dirigiu o Dispensário contra a Tuberculose da capital (Nóbrega, 1979, p.222-223).

${ }_{17}$ Natural de Natal (RN), Lauro Wanderley formou-se em farmácia no Recife e em medicina no Rio de Janeiro. Em 1928, estabeleceu-se na capital da Paraíba com um consultório especializado em "doenças das senhoras, operações e partos". Angariou fama atuando nas instituições públicas e previdenciárias: foi 
cirurgião da Santa Casa de Misericórdia, do serviço de Assistência Pública de João Pessoa e do Instituto de Aposentadoria e Pensões dos Industriários. Exerceu o cargo de presidente da Sociedade de Medicina e Cirurgia e foi um assíduo colaborador da Revista Medicina. Também investiu na carreira política, elegendose, em 1934, deputado estadual pela Liga Eleitoral Católica (Nóbrega, 1979, p.265-266).

${ }^{18}$ Formado em medicina pela Faculdade do Rio de Janeiro, o doutor João Soares notabilizou-se como um dos principais pediatras da capital paraibana nos anos 1930. Além do consultório particular, atuou em várias instituições públicas: Centro de Saúde da capital, Centro de Puericultura de Cruz das Almas, Instituto de Proteção e Assistência à Infância, Assistência Pública Municipal de João Pessoa, Diretoria de Saúde Pública da Paraíba (Nóbrega, 1979, p.159-160).

${ }^{19}$ Segundo Nóbrega (1979, p.252-253), o doutor Octavio Soares "foi, possivelmente, o primeiro psiquiatra que clinicou nesta capital". Formado em farmácia pela Faculdade da Bahia e em medicina pela do Rio de Janeiro, foi um dos fundadores da Sociedade de Medicina e Cirurgia da Paraíba. Nos anos 1930, destacou-se no setor público, compondo os quadros técnicos da Diretoria de Saúde Pública da Paraíba, quando dirigiu os postos de higiene nos municípios de Conceição, Mamanguape e Monteiro.

${ }^{20}$ Identificamos uma doação de $100 \$ 000$ (cem mil réis) da Empresa Tração, Luz e Força (Posto Médico..., 14 jan. 1933).

${ }^{21}$ Em 27 de dezembro de 1933, a Companhia de Teatro Lyson Gaster realizou uma apresentação no Teatro Santa Rosa, na capital, cuja renda foi revertida em prol do Hospital Proletário (Cf. Espetáculo..., 24 dez. 1933 e Hospital..., 18 fev. 1934).

22 Sobre os problemas da saúde pública paraibana durante os anos 1930, ver Soares Júnior (2015) e Nascimento (2019).

${ }^{23}$ Durante o nosso recorte, a Assistência Pública Municipal de João Pessoa era o órgão responsável pela gestão e execução da política de saúde no município da capital (Castro, 1945, p.387-400).

${ }^{24}$ Walfredo Guedes Pereira formou-se em medicina no Rio de Janeiro (1907). Na Paraíba, destacou-se como pediatra. Idealizou o Instituto de Proteção e Assistência à Infância, fundado na capital em $1^{\circ}$ de novembro de 1912 para o atendimento de crianças e parturientes de baixa renda, tendo sido o diretor desta instituição desde a sua criação até 1949. Entre 1920 e 1924 foi prefeito da capital, tendo implementado uma reforma urbana que lhe valeu o epíteto de "o Pereira Passos de João Pessoa". Entre 1925 e 1930 dirigiu os serviços da Comissão Federal de Saneamento e Profilaxia Rural na Paraíba, tendo ainda chefiado a Diretoria de Saúde Pública da Paraíba entre 1930 e 1935 (Nóbrega, 1979, p.236-239).

${ }^{25}$ Segundo Singer (2012, p.191), na sociedade capitalista, a diferença básica entre as classes trabalhadoras e as classes proprietárias é que, ao contrário das primeiras, estas dispõem de "posses econômicas suficientes para assegurar a satisfação de suas necessidades e das de seus dependentes, sem que tenham necessidade de exercer alguma atividade remunerada". Já os trabalhadores, "por não terem tais posses subsistem com os ganhos do exercício de atividade remunerada". Tal definição encerra um conceito complexo e plural de classes sociais, não admitindo a ideia de "classe trabalhadora" no singular.

${ }^{26}$ A formação da medicina social ocorreu em três etapas: a medicina social de Estado, que se desenvolveu na Alemanha no começo do século XVIII; a medicina social urbana, que apareceu na França em fins do século XVIII; e a medicina social da força de trabalho, que surgiu na Inglaterra no século XIX (Foucault, 2017, p.143-170).

${ }^{27}$ Segundo Foucault (2017, p.188): “É então que o saber médico que, até o início do século XVIII, estava localizado nos livros, em uma espécie de jurisprudência médica encontrada nos grandes tratados clássicos da medicina, começa a ter seu lugar, não mais no livro, mas no hospital; não mais no que foi escrito e impresso, mas no que é cotidianamente registrado na tradição viva, ativa e atual que é o hospital".

${ }^{28}$ Sobre os atendimentos no Posto Médico, só encontramos pequenos boletins semanais, publicados por A União, contendo o número de atendimentos (Hospital..., 6 fev. 1934).

${ }^{29}$ Esse tipo de abordagem "publicitária" foi recorrente. Entre outras notícias com esse perfil, podemos citar: Posto Médico... (27 jan. 1933, 29 jan. 1933, 8 fev. 1933) e Hospital... (9 fev. 1933, 24 fev. 1933).

${ }^{30}$ Para abordar esse evento, analisamos as seguintes notícias: Festival... (29 mar. 1934), Festival artístico... (1 abr. 1934, 13 abr. 1934), O festival... (8 abr. 1934), O próximo... (11 abr. 1934), O festival de hoje... (14 abr. 1934), A festa... (15 abr. 1934, 17 abr. 1934) e Em benefício... (18 maio 1934).

${ }^{31}$ A partir de 1934, não encontramos mais referência ao Hospital Proletário na documentação. Além disso, Castro (1945), Nóbrega (1979) e Mendonça (2004), fontes importantes da história da saúde na Paraíba, não mencionam tal instituição. 


\begin{abstract}
${ }^{32}$ Não encontramos mais informações sobre o doutor Aluisio Raposo. Sabemos apenas que ele trabalhava como ginecologista na capital, atuando na sua clínica particular, no Hospital da Santa Casa de Misericórdia e no serviço de Assistência Pública Municipal de João Pessoa (Dr. Aluizio..., 24 out. 1936).

${ }^{33}$ A respeito dos serviços prestados no Posto, cf.: Hospital... (6 fev. 1934, 13 mar. 1934, 3 abr. 1934, 15 abr. 1934, 13 maio 1934).

${ }^{34}$ A União publicou pequenos reclames com essa finalidade em suas edições de 30 de janeiro de 1934 e 10 de fevereiro de 1934.

${ }^{35}$ Fora do jornal $A$ União, a única menção mais consistente ao Hospital Proletário e a seu Posto Médico encontra-se em Cavalcante Neto (2013, p.175). Mesmo assim, o autor também baseia-se nesse jornal para abordar o assunto. Além disso, ele também indica que o tema só aparece no periódico entre 1930 e 1934.

${ }^{36}$ Empregamos esse conceito conforme Latour (1994). Para ele, a modernidade tem como caraterística sua obsessão por "purificar" os diversos aspectos da experiência humana. Entre outras operações, esse processo implica separar, classificar e hierarquizar os mínimos detalhes da existência. Contudo, como no caso do Hospital Proletário, a modernidade jamais conseguiu "purificar" de fato as realidades híbridas que a constituem.
\end{abstract}

\title{
REFERÊNCIAS
}

A FESTA...

A festa em benefício do Hospital Proletário João Pessoa. A União, p.3. 17 abr. 1934.

A FESTA...

A festa em benefício do Hospital Proletário. $A$ União, p.1. 15 abr. 1934.

A INAUGURAÇÃO...

A inauguração do Posto Médico do Hospital Proletário João Pessoa. A União, p.8. 13 dez. 1933.

AIRES, José Luciano.

Cenas de um espetáculo político: poder, memória e comemorações na Paraíba (1935-1945). Tese (Doutorado) - Centro de Filosofia e Ciências Humanas, Universidade Federal de Pernambuco, Recife. 2012.

AMPARO...

Amparo que enobrece; solidariedade que define. A União, p.3. 18 abr. 1934.

A PRÓXIMA INSTALAÇÃO...

A próxima instalação de um posto médico do futuro Hospital Proletário João Pessoa. A União, p.8. 21 dez. 1932.

ARAÚJO, Fátima.

Paraíba, imprensa e vida: jornalismo impresso (1826 a 1986). João Pessoa: Grafset. 1986.

ASSEMBLEIA LEGISLATIVA...

Assembleia Legislativa. A União, p.3. 25 set. 1930.

BENEMÉRITA REALIZAÇÃO...

Benemérita realização do operariado paraibano. A União, p.1. 12 dez. 1933.

CAPONI, Sandra.

Da compaixão à solidariedade: uma genealogia da assistência médica. Rio de Janeiro: Editora Fiocruz. 2000.
CASTRO, Oscar de.

Medicina na Paraíba: flagrantes da sua evolução. João Pessoa: A União. 1945.

CASTRO, Oscar de.

Relatório da Diretoria de Assistência Pública

Municipal de João Pessoa: referente ao movimento daquela repartição em 1935. João Pessoa: Imprensa Oficial. 1936.

CAVALCANTE NETO, Faustino.

A ameaça vermelha: o imaginário anticomunista na Paraíba, 1917-1937. Tese (Doutorado em História) - Universidade Federal de Pernambuco, Recife. 2013.

CHAGAS, Waldeci.

As singularidades da modernização na Cidade da Paraíba nas décadas de 1910 a 1930. Tese (Doutorado em História) - Universidade Federal de Pernambuco, Recife. 2004.

CHALHOUB, Sidney.

Trabalho, lar e botequim: o cotidiano dos trabalhadores no Rio de Janeiro da Belle Époque. Campinas: Editora da Unicamp. 2012.

DECRETO N.244...

Decreto n.244, de 31 de dezembro de 1931. A União, p.9. 1 jan. 1932.

DECRETO N.355...

Decreto n.355, de 31 de dezembro de 1932. A União, p.6. 1 jan. 1933.

DINIZ, Ariosvaldo.

A maldição do trabalho: homens pobres, mendigos, ladrões no imaginário das elites nordestinas (1850-1930). João Pessoa: Manufatura. 2004. 
DR. ALUIZIO...

Dr. Aluizio Raposo. A União, p.5. 24 out. 1936.

DR. EVILÁSIO...

Dr. Evilásio Pessoa. A União, p.3. 17 mar. 1932.

EM BENEFÍCIO...

Em benefício do Hospital Proletário João Pessoa.

A União, p.1. 18 maio 1934.

ESPETÁCULO...

Espetáculo em benefício do Hospital Proletário João Pessoa. A União, p.3. 24 dez. 1933.

ESTATUTOS...

Estatutos da Confederação Operária Beneficente. A União, p.7. 17 set. 1930.

FESTIVAL...

Festival em benefício do Hospital Proletário João Pessoa. A União, p.1. 29 mar. 1934.

FESTIVAL ARTÍSTICO...

Festival artístico desportivo em benefício do

Hospital Proletário. A União, p.1. 13 abr. 1934.

FESTIVAL ARTÍSTICO...

Festival artístico desportivo. A União, p.1. 1 abr. 1934.

FIGUEIRÊDO, Márcio.

"Solidários nos demos as mãos": as associações mutualistas de trabalhadores na Paraíba do Norte (1881-1910). João Pessoa: Dissertação (Mestrado em História) - Universidade Federal da Paraíba, João Pessoa. 2016.

FONSECA, Cristina.

Saúde no governo Vargas, 1930-1945: dualidade institucional de um bem público. Rio de Janeiro: Editora Fiocruz. 2007.

FOUCAULT, Michel.

Microfísica do poder. Organização, introdução e revisão técnica, Roberto Machado. Rio de Janeiro: Paz e Terra. 2017.

GOMES, Angela de Castro.

Ideologia e trabalho no Estado Novo. In: Pandolfi, Dulce (Org.). Repensando o Estado Novo. Rio de Janeiro: FGV Editora. p.53-72. 1999.

GOMES, Angela de Castro.

A invenção do trabalhismo. Rio de Janeiro:

Relume-Dumará. 1994.

GURJÃO, Eliete.

Morte e vida das oligarquias, Paraíba (1889-1945). João Pessoa: Editora Universitária da UFPB. 1994.

HARDMAN, Francisco Foot; LEONARDI, Victor. História da indústria e do trabalho no Brasil. São Paulo: Ática. 1991.

HIGIENE...

Higiene nova. A União, p.1. 21 fev. 1932.
HOCHMAN, Gilberto.

A Era do Saneamento: as bases da política de saúde pública no Brasil. São Paulo: Hucitec. 2006.

HOSPITAL...

Hospital Proletário. A União, p.5. 13 maio 1934.

HOSPITAL...

Hospital Proletário João Pessoa. A União, p.1. 4 maio 1934.

HOSPITAL...

Hospital Proletário. A União, p.8. 15 abr. 1934.

HOSPITAL...

Hospital Proletário. A União, p.3. 3 abr. 1934.

HOSPITAL...

Hospital Proletário João Pessoa. A União, p.5. 13 mar. 1934.

HOSPITAL...

Hospital Proletário João Pessoa. A União, p.8. 2 mar. 1934.

HOSPITAL...

Hospital Proletário João Pessoa. A União, p.1. 23 fev. 1934.

HOSPITAL...

Hospital Proletário João Pessoa. A União, p.8. 18 fev. 1934.

HOSPITAL...

Hospital Proletário João Pessoa. A União, p.12. 10 fev. 1934.

HOSPITAL...

Hospital Proletário João Pessoa: boletim semanal. A União, p.7. 6 fev. 1934.

HOSPITAL...

Hospital Proletário João Pessoa. A União, p.3. 26 jan. 1934.

HOSPITAL...

Hospital Proletário João Pessoa. A União, p.8. 19 mar. 1933.

HOSPITAL...

Hospital Proletário João Pessoa: os srs. R.

Aubertel \& Cia. Ltda., do Rio, fazem importante dádiva. A União, p.8. 11 mar. 1933.

HOSPITAL...

Hospital Proletário João Pessoa: a contribuição dos operários da Empresa Cearense. A União, p.8. 3 mar. 1933.

HOSPITAL...

Hospital Proletário João Pessoa. A União, p.1. 24 fev. 1933.

HOSPITAL...

Hospital Proletário João Pessoa: importante contribuição dos srs. Hyman Rinder \& Cia., do Rio de Janeiro. A União, p.1. 21 fev. 1933. 
HOSPITAL...

Hospital Proletário João Pessoa. A União, p.1. 18 fev. 1933

HOSPITAL...

Hospital Proletário João Pessoa. A União, p.8. 9 fev. 1933.

HOSPITAL...

Hospital Proletário João Pessoa. A União, p.5. 7 fev. 1933.

HOSPITAL...

Hospital Proletário João Pessoa. A União, p.12. 4 dez. 1930.

HOSPITAL...

Hospital Proletário João Pessoa. A União, p.2. 17 set. 1930.

HOSPITAL...

Hospital Proletário João Pessoa. A União, p.3. 16 set. 1930 .

\section{LATOUR, Bruno.}

Jamais fomos modernos: ensaio de antropologia simétrica. Rio de Janeiro: Editora 34. 1994.

LOUVÁVEL INICIATIVA...

Louvável iniciativa. A União, p.7. 30 set. 1933.

MARTINS, Eduardo.

A União: jornal e história da Paraíba, sua evolução gráfica e editorial. João Pessoa: A União. 1977.

MENDONÇA, Delosmar.

História dos hospitais da capital paraibana. João Pessoa: Sal da Terra. 2004.

MENSAGEM...

Mensagem do Exmo. Sr. Governador Argemiro de Figueirêdo à Assembleia Legislativa do Estado. A União, p.4. 2 out. 1935.

NASCIMENTO, Emanoel.

"A lepra e a ordem": uma história da construção do Hospital Colônia Getúlio Vargas, Paraíba (1929-1941). Dissertação (Mestrado em História) - Universidade Federal da Paraíba, João Pessoa. 2019.

NÓBREGA, Humberto.

As raízes da ciência da saúde na Paraíba:

medicina, farmácia, odontologia e enfermagem. João Pessoa: Editora Universitária da UFPB. 1979.

O FESTIVAL...

O festival em benefício do Hospital Proletário João Pessoa. A União, p.5. 8 abr. 1934.

O FESTIVAL DE HOJE..

O festival de hoje e amanhã, em benefício do Hospital Proletário. A União, p.8. 14 abr. 1934.
O HOSPITAL...

O Hospital Proletário João Pessoa inaugura hoje seu primeiro posto de assistência médica. $A$

União, p.8. 10 dez. 1933.

O PRÓXIMO...

O próximo grande festival em benefício do

Hospital Proletário João Pessoa. A União, p.1. 11 abr. 1934.

PEREIRA NETO, André.

Ser médico no Brasil: o presente no passado. Rio de Janeiro: Editora Fiocruz. 2001.

POSTO MÉDICO...

Posto Médico do Hospital Proletário João Pessoa. A União, p.1. 8 fev. 1933.

POSTO MÉDICO...

Posto Médico do Hospital Proletário João Pessoa. A União, p.8. 29 jan. 1933.

POSTO MÉDICO...

Posto Médico do Hospital Proletário João Pessoa. A União, p.1. 27 jan. 1933.

POSTO MÉDICO...

Posto Médico do Hospital Proletário João Pessoa. A União, p.8. 14 jan. 1933.

POSTO MÉDICO...

Posto Médico do Hospital Proletário João Pessoa. A União, p.1. 12 jan. 1933.

POSTO MÉDICO...

Posto Médico do Hospital Proletário João Pessoa. A União, p.8. 10 jan. 1933.

POSTO MÉDICO...

Posto Médico do Hospital Proletário João Pessoa. A União, p.1. 5 jan. 1933.

POSTO MÉDICO...

Posto Médico do Hospital Proletário João Pessoa. A União, p.1. 28 dez. 1932.

POSTO MÉDICO...

Posto Médico do Hospital Proletário João Pessoa: uma comissão de operários é recebida pelo interventor Gratuliano de Brito. A União, p.8. 27 dez. 1932.

PRECISAMOS DE HOSPITAIS...

Precisamos de hospitais. A União, p.3. 24 maio 1934.

RELATÓRIO...

Relatório apresentado pelo Dr. Walfredo Guedes Pereira, diretor geral da Saúde Pública, ao senhor Dr. Secretário do Interior e Segurança Pública, correspondente ao ano de 1933. A União, p.9. 4 maio 1934.

SANTANA, Martha Falcão.

Poder e intervenção estatal (Paraíba: 1930-1940). João Pessoa: Editora Universitária da UFPB. 2000. 
SANTOS, Leonardo dos.

Entre a ciência e a saúde pública: a construção do médico paraibano como reformador social (1911-1929). Dissertação (Mestrado em História) - Universidade Federal de Campina Grande, Campina Grande. 2015.

SANTOS, Wanderley Guilherme dos.

Cidadania e justiça: a política social na ordem brasileira. Rio de Janeiro: Campus. 1979.

SINGER, Paul.

A cidadania para todos. In: Pinsky, Jaime; Pinsky, Carla (Org.). História da cidadania. São Paulo: Contexto. p.190-263. 2012.

SOARES JÚNIOR, Azemar.

"Physicamente vigorosos": medicalização escolar e modelação dos corpos na Paraíba (1913-1942).
Tese (Doutorado em Educação) - Universidade Federal da Paraíba, João Pessoa. 2015.

SOARES JÚNIOR, Azemar.

Corpos hígidos: o limpo e o sujo na Paraíba (19121924). João Pessoa: Dissertação (Mestrado em História) - Universidade Federal da Paraíba, João Pessoa. 2011.

THOMPSON, Edward.

A miséria da teoria ou um planetário de erros: uma crítica ao pensamento de Althusser. Rio de Janeiro: Zahar. 1981.

VAI SER CONSTRUÍDO...

Vai ser construído nesta capital o Hospital Operário João Pessoa. A União, p.8. 2 set. 1930. 